\title{
Estudos taxonômicos em Gloxinia s.l. (Gesneriaceae) - I: uma nova espécie do Mato Grosso do Sul, Brasil
}

\author{
Taxonomic studies in Gloxinia s.l. (Gesneriaceae) - I: \\ a new species from Mato Grosso do Sul, Brazil
}

Andréa Onofre de Araujo ${ }^{1}$, Vinicius Castro Souza ${ }^{1} \&$ Alain Chautems $^{2}$

\begin{abstract}
Resumo
Gloxinia alterniflora é descrita como uma nova espécie de Gesneriaceae (Gloxinieae). A espécie é comparada com as outras do gênero Gloxinia s. str. através de comentários e uma chave de identificação. Hábitat, ilustração e status de conservação são também apresentados.

Palavras-chave: conservação, Gloxinieae, táxon novo, taxonomia.
\end{abstract}

\begin{abstract}
Gloxinia alterniflora is described as a new species of Gesneriaceae (Gloxinieae) and relationships with the other taxons of Gloxinia s. str. are discussed. An identification key is provided and habitat, illustration and conservation status are also presented.
\end{abstract}

Key words: conservation status, Gloxinieae, taxonomy, new taxon.

\section{Introdução}

Gloxinia foi descrito por L'Héritier (1789), incluindo uma única espécie: Gloxinia maculata (nome ilegítimo; = Martynia perennis L.). Desde a descrição do gênero até o estudo de Wiehler (1976), várias espécies foram descritas em Gloxinia e, anteriormente a 1976, transferidas para outros gêneros: Achimenes P.Br., Eucodonia Hanst., Gesneria L., Kohleria Regel, Paliavana Vand., Pearcea Regel, Sinningia Nees e Smithiantha Kuntze. A maior parte dessas espécies atualmente é reconhecida como sinônimo de Sinningia speciosa (Lodd.) Hiern (ou "gloxínia", nome pelo qual é ainda comercializada nas floriculturas).

Wiehler (1976), baseado principalmente em dados de hibridização experimental, incluiu vários gêneros e alguns subgêneros e seções na sinonímia de Gloxinia: Achimenes subgen.Mandirola (Decne.) Hanst., Achimenes sect. Mandirola (Decne.) Benth., Achimenes sect. Kohleriopsis Fritsch, Achimenes sect. Tydaeopsis Fritsch, Fiebrigia Fritsch,
Fritschantha Kuntze, Kohleria sect. Gloxinella H.E.Moore, Mandirola Decne., Salisia Regel e Seemannia Regel. Portanto, após várias transferências para outros gêneros realizadas anteriormente ao estudo de Wiehler e as modificações propostas por ele, Gloxinia sensu Wiehler (1976), ou Gloxinia s.l., incluiria 15 espécies.

Roalson et al. (2005a), baseados em análises filogenéticas, separaram Gloxinia s. str. de alguns dos gêneros sinonimizados por Wiehler (1976), como por exemplo, Mandirola, Seemannia e Gloxinella (e as respectivas seções e subgêneros). De acordo com a circunscrição adotada por esses autores, Gloxinia (ou Gloxinia s. str.) inclui, além da espécie-tipo (G. perennis (L.) Fritsch), mais duas espécies: Gloxinia erinoides (DC.) Roalson \& Boggan e Gloxinia xanthophylla (Poeppig) Roalson \& Boggan, totalizando três espécies em Gloxinia s. str. Essas duas últimas foram reconhecidas em dois gêneros monoespecíficos sinonímia de Gloxinia s. str. por Roalson et al.

\footnotetext{
${ }^{1}$ Universidade de São Paulo, Escola Superior de Agricultura “Luiz de Queiroz”, Depto. Ciências Biológicas, Av. Pádua Dias 11, 13418-900, Piracicaba, SP, Brasil. Autor para correspondência: aonofrearaujo@yahoo.com.br

${ }^{2}$ Conservatoire \& Jardin botaniques de la Ville de Genève, Impératrice 1, C.P. 60, CH-1292 Chambésy, Genève, Switzerland.
} 
(2005a). Esses autores se basearam, principalmente, em dados de filogenia molecular (Roalson et al. 2005b) para essas sinonimizações. Assim, as 14 espécies restantes reconhecidas por Wiehler (1976, 1983) em Gloxinia s.l. foram posicionadas por Roalson et al. (2005a) nos seguintes gêneros: Gloxinella (1 sp.), Gloxiniopsis Roalson \& Boggan (1 sp.), Mandirola (3 spp.), Monopyle Moritz ex Benth. (1 sp.), Nomopyle Roalson \& Boggan (1 sp.), Seemannia (4 spp.) e Sphaerorrhiza Roalson \& Boggan (2 spp.), além de Gloxinia villosa (Gardner) Wiehler, tratada por esses autores como incertae sedis.

Gloxinia s. str. pode ser diferenciado dos outros gêneros da tribo Gloxinieae pelas florescências bracteosas ou às vezes frondobracteosas, pelo nectário anelar ou este ausente, pelos frutos secos sem tricomas uncinados e sem ruptura do hipanto (deiscente apenas no ápice do fruto) e pela associação entre coloração da corola e margem de seus lobos (quando a corola é rósea ou branca com manchas púrpuras, os lobos apresentam margem inteira, denteada ou fimbriada; quando a corola é totalmente branca, os lobos apresentam margem inteira). $\mathrm{O}$ gênero ocorre desde a floresta atlântica do sudeste do Brasil (sem confirmação de serem populações naturais nessa formação vegetal), alcançando os cerrados do Planalto Brasileiro (em florestas de galeria), com poucas ocorrências na região Amazônica, avançando pela face leste dos Andes até alcançar a região do Caribe, desde a Venezuela até a Guiana Francesa, e também a América Central, do Panamá até Honduras. Os ambientes onde mais comumente encontram-se as espécies desse gênero são as florestas de galeria, cerrados e ambientes com afloramentos rochosos, como os campos rupestres.

O presente trabalho trata-se do primeiro de uma série de resultados encontrados durante estudos realizados pelos autores do presente trabalho, baseados principalmente no estudo taxonômico de Gloxinia s.l. (Araujo 2007). Durante esses estudos, uma nova espécie de Gloxinia s. str. foi identificada e está sendo aqui descrita, juntamente com a apresentação de uma chave para a identificação das quatro espécies do gênero.

\section{Material e Métodos}

Para o desenvolvimento desse trabalho foram consultados vários herbários do Brasil e do exterior, dentre eles CGMS, COR, ESA, G, MBM e NY (Thiers
2009, continuamente atualizado), através de visita pessoal, solicitação de empréstimo ou de imagens digitais disponíveis nos sítios de internet dos herbários. A descrição da espécie foi baseada em material de herbário e os caracteres utilizados na chave de identificação foram obtidos através da análise de espécimes herborizado, em cultivo e/ou em hábitat natural de todas as espécies de Gloxinia s. str.

\section{Resultados}

Gloxinia alterniflora A.O.Araujo \& Chautems, sp. nov. Tipo: BRASIL. MATO GROSSO DO SUL: Bonito, Projeto Guaicurus, afloramentos de calcário da encosta do morro, 14.III.2003, fl. e fr., G. Hatschbach et al. 74705 (holótipo MBM!; isótipo $\mathrm{G}$ !).

Figs. 1, 2

Gloxiniae perenni (L.) Fritsch corolla lilacina vel rosea et nectario absenti similis, sed caudice radicibusque stolonibus filiformibus instructo, cauli piloso, foliis villosis, floribus alternis et laciniis calycis lanosis, multo minoribus $(5-6 \times$ 2-3 $\mathrm{mm}$ vs. 9-17 $\times 4-9 \mathrm{~mm})$ cum marginibus integris differt.

Ervas não-ramificadas, lignificadas, $30-60 \mathrm{~cm}$ alt. Presença de estolões filiformes 3-15 cm compr., na base da planta. Caule com tricomas, avermelhado (quando seco). Internós 4,8-5,2 cm compr. Folhas opostas, com moderada anisofilia; pecíolos 1,3-4 cm compr.; lâminas 5,8-9,5 ×3,5-5,7 cm, elípticas ou ovais, ápice agudo, base simétrica ou assimétrica, cuneada, margem serreada, vilosas em ambas as faces, verdes, 5-7 pares de nervuras secundárias, nenhuma delas partindo do mesmo ponto. Florescência bracteosa, com flores alternas no ramo; brácteas da base das flores ca. 0,6 ×0,2 $\mathrm{cm}$; internó do ramo florífero 0,8-1,1 cm compr. Flores com pedicelo 0,5-1,2 cm compr.; cálice verde, lacínios 0,5-0,6×0,2-0,3 cm, lanados em ambas as faces, obovais a elípticos, com margem inteira; eixo da corola em relação ao pedicelo paralelo; corola campanulado-infundibuliforme com giba na base do tubo na face ventral, tubo lilás, 1,5-1,9 cm compr., internamente glabro, externamente seríceo; fauce não-constricta, 1,8-2 cm diâm.; lobo ventral externamente glabro, lobos laterais e dorsais externamente seríceos, exceto no ápice, internamente todos glabros, 0,7-1 cm compr., margem do lobo ventral fimbriada, dos outros sinuosa; estames 0,7-0,9 cm compr., inclusos, filetes lanados, anteras 4, unidas apicalmente, estaminódio presente; nectário ausente; ovário ínfero; estilete 


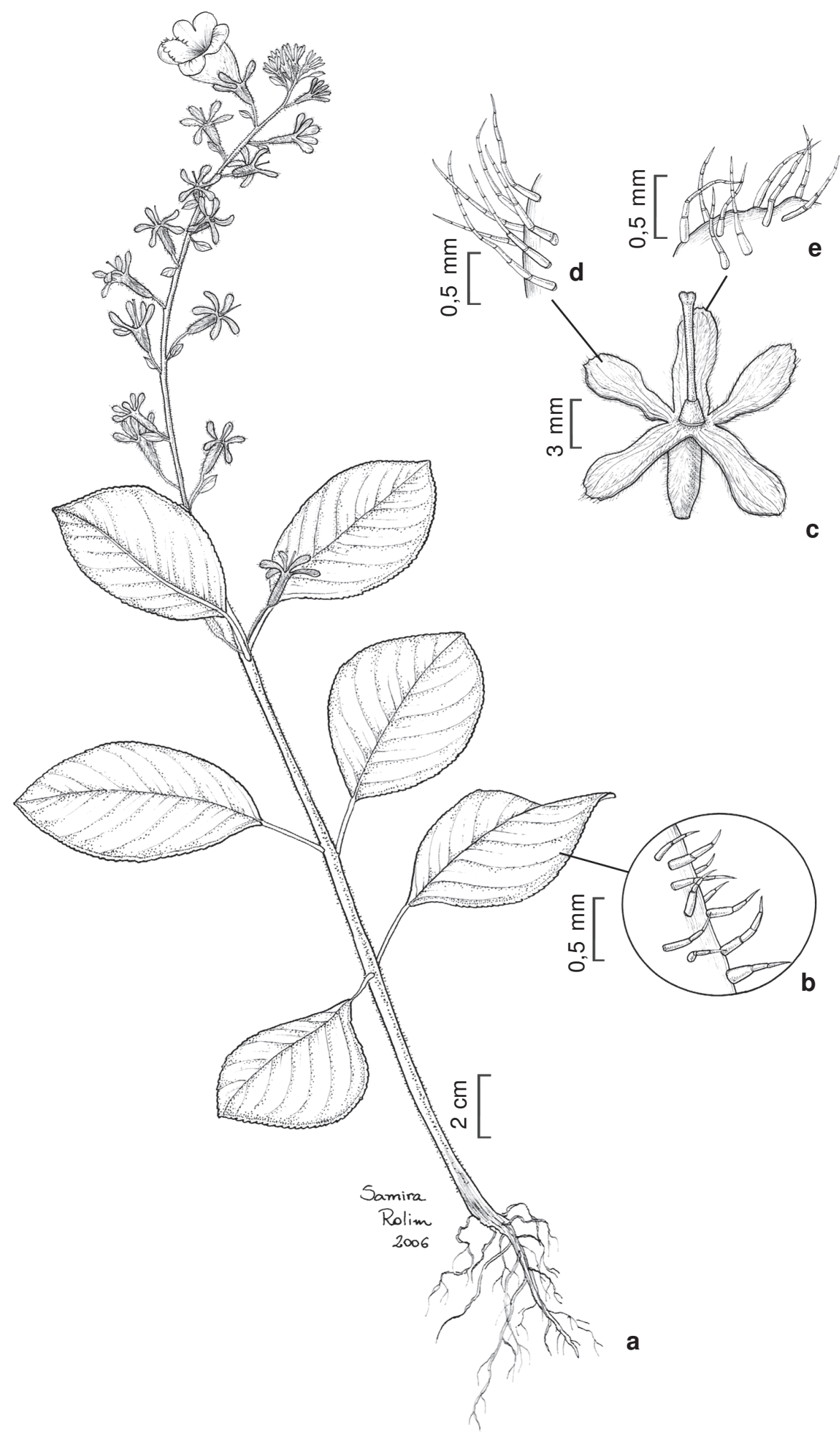

Figura 1 - Gloxinia alterniflora A.O.Araujo \& Chautems - a. hábito; b. detalhe dos tricomas da folha; c. cálice e gineceu (corola e estames removidos); d. indumento interno do cálice; e. indumento externo do cálice (Hatschbach 74705 ). Figure 1- Gloxinia alterniflora A.O.Araujo \& Chautems - a. habit; b. detail of leaf trichomes; c. calyx and gynoecium (corolla and stamens removed); d. calyx inner indument; e. calyx outer indument (Hatschbach 74705). 


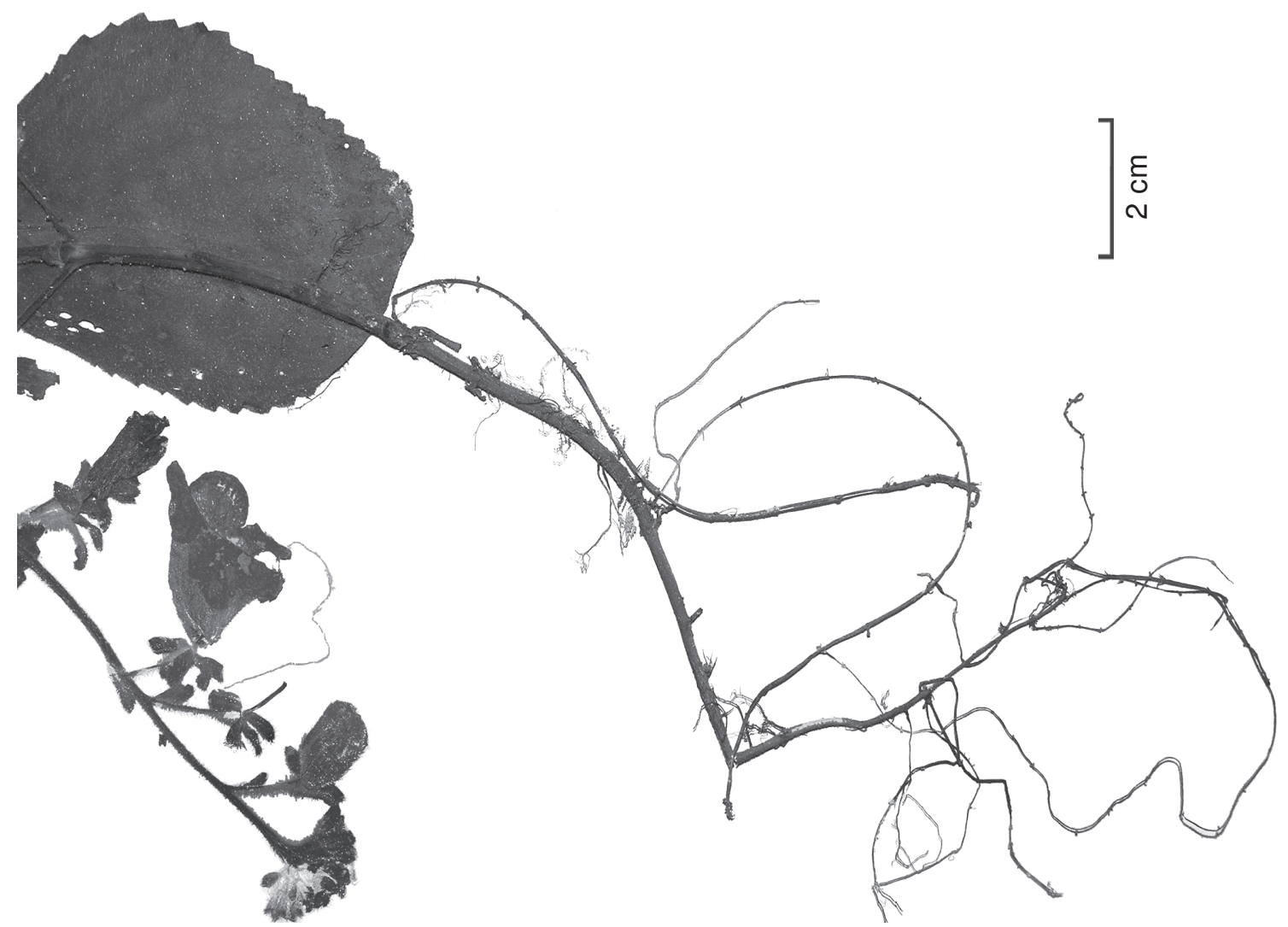

Figura 2 - Gloxinia alterniflora A.O.Araujo \& Chautems - Base da planta, evidenciando o estolão e as raízes fibrosas (Hatschbach 74705).

Figure 2 - Gloxinia alterniflora A.O.Araujo \& Chautems - Base of the plant, showing the stolon and the fibrous roots ( Hatschbach 74705).

pubescente com tricomas glandulares. Cápsula 1$1,7 \times 0,3-0,4 \mathrm{~cm}$ incluindo hipanto de até $1 \mathrm{~cm}$ compr., lanada, cilíndrica, ápice voltado para cima e aberto apenas nessa parte, costas pouco proeminentes.

Até o momento, foi encontrada apenas no Mato Grosso do Sul, ocorrendo em afloramento calcário de encosta de serra. Gloxinia perennis é a espécie morfologicamente mais próxima, porém não ocorre no Mato Grosso do Sul, apesar de ter uma ampla distibuição entre o Mato Grosso e a América Central.

Quanto ao seu status de conservação, é considerada como criticamente em perigo, de acordo com o critério de extensão de ocorrência menor que $100 \mathrm{~km}^{2}$ (IUCN 2001).

O epíteto específico refere-se à disposição das flores na florescência de forma alterna, o que auxilia na diferenciação da espécie mais próxima (Gloxinia perennis) que apresenta as flores sempre opostas.
A florescência bracteosa (Fig. 1a), a coloração da corola, a margem dos lobos da corola (Fig. 1a) e o tipo de fruto são caracteres marcantes que fazem com que essa espécie seja incluída em Gloxinia s. str. Um caráter diferencial de $G$. alterniflora em relação ao restante das espécies do gênero é a presença de estolões filiformes (Fig. 2). Esse caráter é comum em outros gêneros de Gloxinieae (como Seemannia), mas não em Gloxinia. O caráter mais comum neste gênero é a presença de rizoma escamoso (ausente em $G$. alterniflora e em G. xanthophylla). Esse tipo de estrutura diferencia-se do estolão pelos catafilos carnosos e internós bastante curtos. Gloxinia alterniflora é muito semelhante à G. perennis, porém vários caracteres diferenciam claramente as duas espécies: estolões, rizoma, indumento da planta como um todo, disposição das flores, tamanho das brácteas e tamanho e margem dos lacínios do cálice (Tab. 1; Figs. 1 e 2). Entre $G$. alterniflora e G. perennis não ocorre sobreposição 
e nem mesmo um contínuo desses caracteres. Dessa forma, apesar de algumas semelhanças entre essas duas espécies, excluiu-se a opção de reconhecimento do espécime Hatschbach 74705 como uma subespécie ou variedade de $G$. perennis. Com a observação dessas diferenças e considerando também a delimitação, as diferenças e semelhanças encontradas entre espécies de Gesneriaceae como um todo, o reconhecimento de G. alterniflora como uma nova espécie fica plenamente justificado. G. erinoides geralmente assemelha-se a $G$. alterniflora pela disposição alterna das flores na florescência, mas essa primeira espécie também pode raramente apresentar flores opostas. Vale ressaltar que um híbrido entre G. perennis e G. erinoides produzido artificialmente e registrado pelo nome "Dragonsong" apresenta florescência com flores alternas, mas o hábito, indumento e tamanho das flores divergem muito de G. alterniflora. Provavelmente esse caráter comum entre $G$. alterniflora e o híbrido foi devido à presença desse caráter também em um dos parentais ( $G$. erinoides). Apesar desse caráter ser instável tanto em G. erinoides (alterna, raramente oposta) quanto em $G$. xanthophylla (alterna, oposta ou verticilada), dentro das outras duas espécies do gênero ele não varia (Tab. 1).

Foi analisada apenas uma coleta de $G$. alterniflora, que diferentemente das outras três espécies do gênero, ainda não se encontra em cultivo. Portanto, caracteres como a coloração detalhada dos ramos e da corola (osmóforo, lobos e fauce) e odor das flores não são conhecidos, pois não são citados na ficha de coleta; nesta, apenas consta que a planta é uma erva ereta e com corola lilás, além de dados do ambiente, local e data da coleta. Quanto ao odor, será um caráter importante a ser verificado na oportunidade de novas coletas, já que as duas espécies mais comuns de Gloxinia s. str. apresentam odor marcante, i.e., parecido com hortelã em $G$. perennis e semelhante ao odor adocicado do coco, em G. erinoides.

\section{Chave para as espécies de Gloxinia s. str.}

1. Rizomas ou estolões ausentes; corola totalmente branca; anteras livres. Peru e Equador..... G. xanthophylla

1'. Rizomas ou estolões presentes; corola branca e vinácea ou lilás ou rosada; anteras unidas. Amplamente distribuída pela América Tropical ou endêmica do município de Bonito (Mato Grosso do Sul, Brasil).

2. Corola cilíndrico-bilabiada, branca e vinácea, tubo 0,3-0,5 cm compr.; nectário presente (amplamente distribuída pela América Tropical) G. erinoides

2'. Corola campanulada ou campanulado-infundibuliforme, lilás ou rosada, tubo 1,6-2,4 cm compr.; nectário ausente.

3. Raizes fibrosas e rizomas escamosos na base da planta, estolões ausentes; caule glabro; folhas com face adaxial esparsamente pubescente, face abaxial glabra ou glabrescente; folhas ou brácteas da base das flores $1,4-5,3(-9) \times 0,9-4(-6,8) \mathrm{cm}$; flores opostas na florescência; lacínios 1,3-1,7×0,4-0,9 cm, glabros em ambas as faces, com margem inteira na base e serreada no ápice; fruto glabro ou em algumas partes glabro e outras pubescente. Amplamente distribuída pela América Tropical G. perennis

3'. Raizes fibrosas e estolões filiformes na base da planta, rizomas ausentes; caule com tricomas; folhas vilosas em ambas as faces; brácteas da base das flores ca. 0,6 $\times 0,2 \mathrm{~cm}$ (nunca folhas na base das flores); flores alternas na florescência; lacínios 0,5-0,6 ×0,2$0,3 \mathrm{~cm}$, lanados em ambas as faces, com margem inteira; fruto lanado. Endêmica do município de Bonito (Mato Grosso do Sul, Brasil) G. alterniflora 
Tabela 1 - Comparação morfológica entre Gloxinia alterniflora e G. perennis.

Table 1 - Morphological comparison between Gloxinia alterniflora and G. perennis.

\begin{tabular}{ll}
\hline Gloxinia alterniflora & Gloxinia perennis \\
\hline Presença de estolões & Ausência de estolões \\
Ausência de rizoma & Presença de rizoma \\
Caule com tricomas & Caule glabro \\
Flores com disposição alterna & Flores com disposição oposta \\
Brácteas da base das flores ca. $0,6 \times 0,2 \mathrm{~cm}$, & Folhas ou brácteas da base das flores \\
nunca folhas na base das flores & $1,4-5,3(-9) \times 0,9-4(-6,8) \mathrm{cm}$ \\
Lacínios do cálice lanados, $0,5-0,6 \times 0,2-0,3 \mathrm{~cm}$, & Lacínios do cálice glabros, $1,3-1,7 \times 0,4-0,9 \mathrm{~cm}, \mathrm{com}$ \\
margem inteira & com margem serreada no ápice \\
Fruto lanado & Fruto glabro a parcialmente pubescente \\
\hline
\end{tabular}

\section{Agradecimentos}

Os autores agradecem ao coletor do espécime, Gerdt Guenther Hatschbach, o material gentilmente disponibilizado. Apoio financeiro: FAPESP, International Association for Plant Taxonomy, Elvin McDonald Research Endowment Fund of the Gesneriad Society, Inc.

\section{Referências}

Araujo, A.O. 2007. Estudos taxonômicos em Gloxinia L'Hér. sensu lato (Gesneriaceae). Tese de Doutorado. Universidade de São Paulo, São Paulo, 176p.

IUCN. 2001. IUCN Red List Categories and Criteria: Version 3.1. IUCN Species Survival Commission. IUCN, Gland, Switzerland and Cambridge, UK.

L'Héritier de Brutellle, C.L. 1789. Gloxinia. In: Aiton, W. (ed.). Hortus Kewensis or, a catalogue of the plants cultivated in the Royal Botanic Garden at Kew. Vol. 2. London. 460p.

Roalson, E.H.; Boggan, J.K. \& Skog, L.E. 2005a. Reorganization of tribal and generic boundaries in the Gloxinieae (Gesneriaceae: Gesnerioideae) and the description of a new tribe in the Gesnerioideae, Sphaerorrhizeae. Selbyana 25: 225-238.

Roalson, E.H.; Boggan, J.K.; Skog, L.E. \& Zimmer, E.A. 2005b. Untangling neotropical Gesneriaceae. Selbyana 6: 1-219.

Thiers, B. 2009. [continuamente atualizado]. Index Herbariorum: A global directory of public herbaria and associated staff. New York Botanical Garden's Virtual Herbarium. Disponível em <http://sweetgum. nybg.org/ih/>. Acesso em setembro/2009.

Wiehler, H. 1976. A report on the classification of Achimenes, Eucodonia, Gloxinia, Goyazia and Anetanthus (Gesneriaceae). Selbyana 1: 374-404.

Wiehler, H. 1983. A synopsis of the neotropical Gesneriaceae. Selbyana 6: 1-219. 